\title{
Genetic Diversity Analysis in Brinjal (Solanum melongena L.) Genotypes: A Principal Component Analysis Approach
}

\author{
Savankumar N. Patel ${ }^{1 *}$, Raj C. Popat ${ }^{2}$, Priya A. Patel ${ }^{1}$ and R.D. Vekariya ${ }^{1}$ \\ ${ }^{1}$ Department of Genetics and Plant Breeding, N. M. College of Agriculture, Navsari \\ Agricultural University, Navsari-396 450, India \\ ${ }^{2}$ Department of Agricultural Statistics, N. M. College of Agriculture, Navsari Agricultural \\ University, Navsari-396 450, India \\ *Corresponding author
}

\begin{tabular}{|c|c|}
\hline \multicolumn{2}{|r|}{ A B S T R A C T } \\
\hline & \multirow{6}{*}{$\begin{array}{l}\text { Principal Component Analysis (PCA) is an important statistical tool through which we can } \\
\text { easily access important polygenic characters which are of great importance in a plant } \\
\text { breeding programme. The experiment was conducted with } 35 \text { germplasm accessions of } \\
\text { brinjal to analyze genetic diversity at N. M. College of Agricultural, Navsari Agricultural } \\
\text { University during the kharif season of } 2016 \text {. The observations were recorded on sixteen } \\
\text { different traits. PCA indicated that six components (PC-1 to PC-6) accounted for } 70.73 \% \\
\text { of the total variation among traits in brinjal genotypes. Out of six principal components } \\
\text { retained; PC-1, PC-2 and PC-3 explained } 21.11 \% \text {, } 13.07 \% \text { and } 11.32 \% \text { of the total } \\
\text { variation respectively. The results of PCA indicated that traits like plant height (PH), leaf } \\
\text { area per plant at } 50 \% \text { flowering (LA), transpiration rate at } 50 \% \text { flowering (TR), } \\
\text { chlorophyll content at } 50 \% \text { flowering (CC), number of fruits per plant (NF), fruit girth } \\
\text { (FG), total phenol content (TPC) and total soluble sugar (TSS) could be used to distinguish } \\
\text { the germplasms of brinjal in the heavy rainfall zone of South Gujarat. The result of present } \\
\text { study could be utilized in planning and execution of future breeding strategies in brinjal. }\end{array}$} \\
\hline Keywords & \\
\hline $\begin{array}{l}\text { Brinjal, Principal } \\
\text { component analysis, } \\
\text { Genetic diversity }\end{array}$ & \\
\hline Article Info & \\
\hline $\begin{array}{l}\text { Accepted: } \\
\text { 26 December } 2017 \\
\text { Available Online: } \\
\text { 10 January } 2018\end{array}$ & \\
\hline & \\
\hline
\end{tabular}

\section{Introduction}

Brinjal (Solanum melongena L.), also known as aubergine, eggplant or guinea squash is an economically important vegetable crop widely cultivated in the tropics, subtropics and warm temperate regions (Sihachakr et al., 1994). It belongs to the family Solanaceae with chromosome number $2 \mathrm{n}=24$. Based upon its highest production potential and availability of produce to consumer, it is also termed as poor man's vegetable. It originated from South East Asia (Lester and Hasan 1991). The annual production of brinjal in India was 12,987 thousand MT from an area of 680 thousand ha in the year 2015 (Anonymous, 2015). Brinjal is a herbaceous annual with erect or semi spreading habits. It is perennial plant but cultivated as annual. It is a warm season crop, adapted to a wide range of climatic conditions 
of the country. Brinjal is an important commercial crop grown all over the country except on higher altitudes. It has high yielding potential and adaptability to various agroclimatic conditions throughout the year. It is grown as summer crop in hilly regions. Besides being used as an important vegetable, eggplant has been extensively exploited in traditional medicine for treatment of many diseases (Kashyap et al., 2003). Brinjal has three main botanical varieties under the species melongena, the round or egg shaped cultivars are grouped under var. esculentum, the long slender type are under var. serpentinum and the dwarf brinjal plant put under var. depressum (Salunkhe and Kadam, 1998).

PCA helps researcher to differentiate significant relationships between traits. Cluster analysis is also an appropriate method for detecting family relationships but the main advantage of using PCA over cluster analysis is that each genotype can be assigned to one group only. The main objective of this study is to access the potential genetic diversity among brinjal genotypes for selection of parents in hybridization programme to obtain better segregants in advanced generation.

\section{Materials and Methods}

The experiment was carried out at N. M. College of Agriculture, Navsari Agricultural University, Navsari during kharif season of year 2016. The experimental material for present investigation consisted of 35 genotypes of brinjal (Solanum melongena L.) obtained from Vegetable Research Scheme, ASPEE College of Horticulture and Forestry, N.A.U., Navsari during the year 2015-16. Observations on sixteen characters were recorded from randomly selected five competitive plants in each plot in all the three replications viz. days to $50 \%$ of flowering (DF), plant height $(\mathrm{PH})$, number of branches per plant (NB), leaf area per plant at $50 \%$ flowering (LA), transpiration rate at $50 \%$ flowering (TR), photosynthetic rate at $50 \%$ flowering (PR), chlorophyll content at $50 \%$ flowering (CC), stomatal conductance at 50\% flowering (SC), number of fruits per plant (NF), number of seeds per fruit (NS), fruit length (FL), fruit girth (FG), average fruit weight (FW), fruit yield per plant (FY), total phenol content (TPC), total soluble sugar (TSS). The PCA method explained by Harman (1976) was followed in the extraction of the principal components.PCA was performed using $\mathrm{R}$ and $\mathrm{R}$-studio software.

\section{Results and Discussion}

\section{Correlation studies}

Pair panels for $16 \times 16$ matrices represents Pearson correlation, histogram and bivariate scatter plot of sixteen traits of brinjal (Fig. 1.). The row and column elements are for the following sixteen traits in sequence viz., days to $50 \%$ of flowering (DF), plant height $(\mathrm{PH})$, number of branches per plant (NB), leaf area per plant at $50 \%$ flowering (LA), transpiration rate at $50 \%$ flowering (TR), photosynthetic rate at $50 \%$ flowering (PR), chlorophyll content at $50 \%$ flowering (CC), stomatal conductance at $50 \%$ flowering (SC), number of fruits per plant (NF), number of seeds per fruit (NS), fruit length (FL), fruit girth $(\mathrm{FG})$, average fruit weight (FW), fruit yield per plant (FY), total phenol content (TPC), total soluble sugar (TSS).Upper half represents correlation coefficients while the lower half represents bivariate scatter plot among different variables.

Diagonal elements represent distribution of different traits. Significant correlation was observed among thirteen pairs of traits out of which highest correlation was observed between fruit girth (FG) and average fruit weight $(\mathrm{FW})$. 
Table.1 Principal components showing the Eigen values, proportion of variance explained and cumulative variance

\begin{tabular}{|l|c|c|c|}
\hline Principal component & Eigen value & $\begin{array}{c}\text { Proportion of } \\
\text { variance }\end{array}$ & $\begin{array}{c}\text { Cumulative } \\
\text { variance (\%) }\end{array}$ \\
\hline $\mathbf{1}$ & 1.8377 & 21.11 & 21.11 \\
\hline $\mathbf{2}$ & 1.4461 & 13.07 & 34.18 \\
\hline $\mathbf{3}$ & 1.3460 & 11.32 & 45.5 \\
\hline $\mathbf{4}$ & 1.2541 & 9.83 & 55.33 \\
\hline $\mathbf{5}$ & 1.1397 & 8.11 & 63.45 \\
\hline $\mathbf{6}$ & 1.080 & 7.29 & 70.74 \\
\hline $\mathbf{7}$ & 0.9931 & 6.16 & 76.91 \\
\hline $\mathbf{8}$ & 0.9252 & 5.35 & 82.26 \\
\hline $\mathbf{9}$ & 0.9055 & 5.12 & 87.38 \\
\hline $\mathbf{1 0}$ & 0.7827 & 3.83 & 91.22 \\
\hline $\mathbf{1 1}$ & 0.6542 & 2.67 & 93.89 \\
\hline $\mathbf{1 2}$ & 0.5316 & 1.76 & 95.65 \\
\hline $\mathbf{1 3}$ & 0.5286 & 1.74 & 97.40 \\
\hline $\mathbf{1 4}$ & 0.4224 & 1.11 & 98.52 \\
\hline $\mathbf{1 5}$ & 0.3966 & 0.98 & 99.50 \\
\hline $\mathbf{1 6}$ & 0.2816 & 0.004 & 100 \\
\hline
\end{tabular}

Table.2 Principal component analysis for 16 quantitative traits in 35 brinjal genotypes nonrotated loadings

\begin{tabular}{|c|c|c|c|c|c|c|}
\hline Particulars & PC 1 & PC 2 & PC 3 & PC 4 & PC 5 & PC 6 \\
\hline DF & 0.4288 & -0.1979 & 0.0776 & -0.0813 & 0.0203 & -0.1958 \\
\hline PH & 0.1308 & 0.1437 & 0.4101 & 0.4105 & -0.1678 & 0.3025 \\
\hline NB & 0.1016 & -0.1228 & 0.5204 & -0.2125 & -0.1548 & -0.2417 \\
\hline LA & 0.3485 & -0.1013 & -0.2465 & 0.2617 & -0.1701 & -0.1346 \\
\hline TR & -0.1891 & 0.2212 & -0.0413 & 0.2102 & -0.6435 & -0.1298 \\
\hline PR & 0.2290 & 0.0128 & -0.4666 & 0.1360 & -0.0446 & 0.0802 \\
\hline CC & 0.1810 & 0.1599 & -0.3284 & 0.0888 & 0.2752 & 0.2169 \\
\hline SC & -0.0174 & 0.3702 & -0.0901 & -0.0936 & -0.0295 & -0.5640 \\
\hline NF & -0.2180 & 0.2549 & 0.1352 & 0.1047 & 0.5225 & -0.1051 \\
\hline NS & 0.3242 & -0.2103 & 0.1630 & -0.2026 & 0.0979 & 0.1357 \\
\hline FL & -0.0316 & -0.4115 & 0.0942 & 0.4783 & 0.0886 & 0.1003 \\
\hline FG & 0.3291 & 0.4378 & 0.0045 & 0.0538 & 0.0634 & -0.0007 \\
\hline FW & 0.4116 & 0.1669 & 0.0973 & 0.0714 & -0.1713 & 0.0199 \\
\hline FY & 0.1843 & 0.0377 & -0.0657 & -0.5448 & -0.1192 & 0.2619 \\
\hline TPC & 0.2676 & 0.2051 & 0.2492 & 0.2001 & 0.2875 & -0.2062 \\
\hline TSS & -0.0821 & 0.4016 & 0.1697 & -0.0772 & -0.0698 & 0.5037 \\
\hline
\end{tabular}


Fig.1 Pair panels for 16X16 matrices represent Pearson correlation, histogram and bivariate scatterplot among the morphological characters

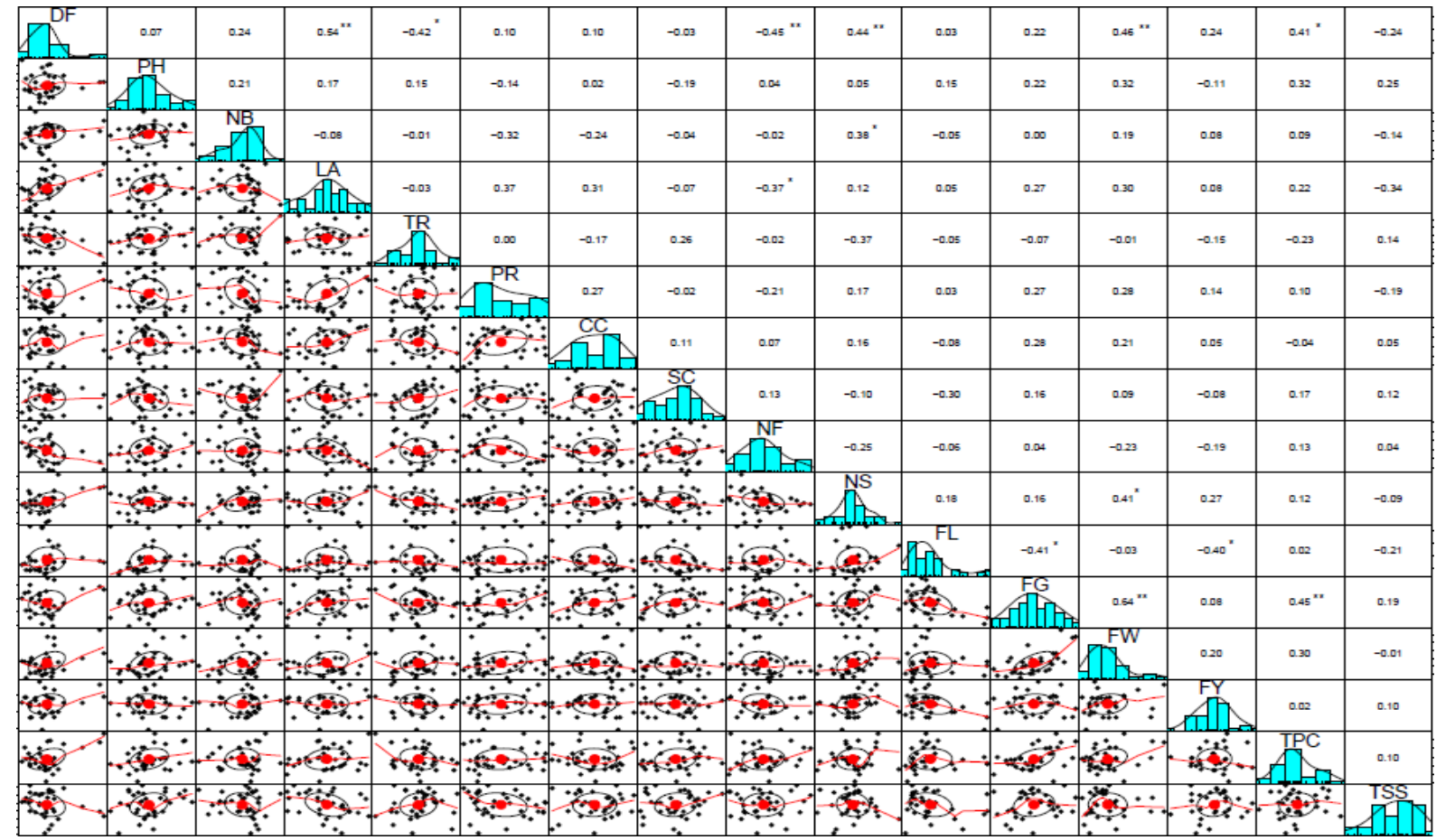

* indicates significance at $\mathrm{p}=0.05, * *$ indicates significance at $\mathrm{p}=0.01$.

Fig.2 3D scatter diagram of 35 genotypes of brinjal on basis of first three PC scores

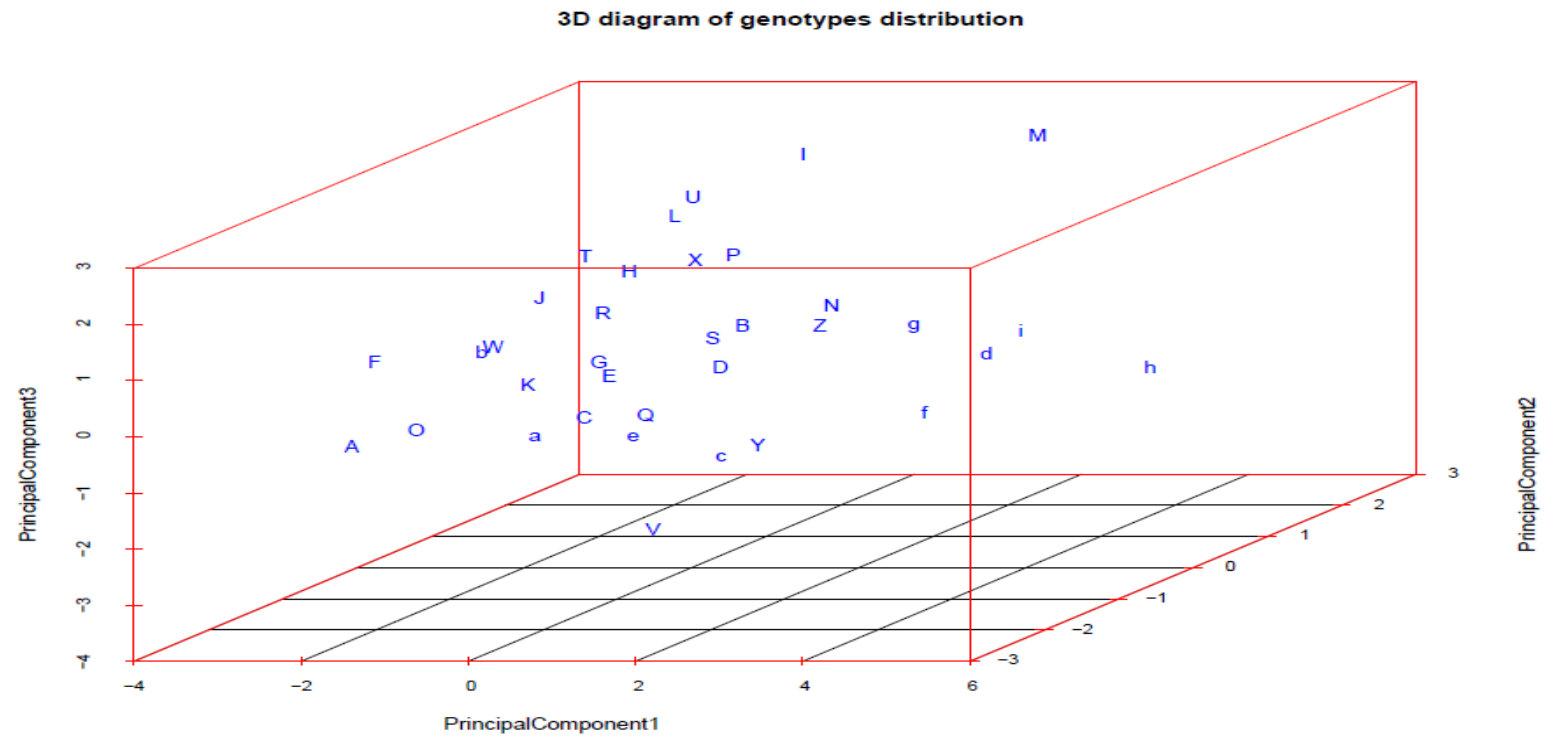

(Here, $\mathrm{A}=\mathrm{NBL}-2, \mathrm{~B}=\mathrm{NBL}-3, \mathrm{C}=\mathrm{NBL}-4, \mathrm{D}=\mathrm{NBL}-6, \mathrm{E}=\mathrm{NBL}-7, \mathrm{~F}=\mathrm{NBL}-8, \mathrm{G}=\mathrm{NBL}-9$, H=NBL-11, I=NBL-12, $\mathrm{J}=\mathrm{NBL}-13, \mathrm{~K}=\mathrm{NBL}-14$,L= NBL-16, M=NBL-22,N= NBL-36, O=NBL-38, P=NBL-39, Q=NBL-40, R=NBL-43, $\mathrm{S}=\mathrm{NBL}-48, \mathrm{~T}=\mathrm{NBL}-49, \mathrm{U}=\mathrm{NBL}-50, \mathrm{~V}=\mathrm{NBL}-51, \mathrm{~W}=\mathrm{NBL}-53, \mathrm{X}=\mathrm{NBL}-54, \mathrm{Y}=\mathrm{NBL}-57, \mathrm{Z}=\mathrm{NBL}-58, \mathrm{a}=\mathrm{NBL}-59$, $\mathrm{b}=\mathrm{NBL}-60, \mathrm{c}=\mathrm{NBL}-61, \mathrm{~d}=\mathrm{NBL}-69$, e=GBL-1 , $\mathrm{f}=\mathrm{GOB}-1, \mathrm{~g}=\mathrm{GJB}-3, \mathrm{~h}=\mathrm{JBGR}-1, \mathrm{i}=\mathrm{GAOB}-2$ ) 


\section{Principal component analysis}

Principal component analysis (PCA) reflects the importance of the largest contributor to the total variation at each axis of differentiation (Sharma, 1998). The Eigen value of a particular principal component depicts the amount of variation explained by that principal component. The sum total of all the Eigen values is equal to the total variance of all sixteen traits (Table 2).

In the present study six principal components PC-1 to PC-6, were extracted from the original data set having eigen values greater than one (Kaiser, 1960). These six principal components account for $70.74 \%$ of the total variation (Table 1). Figure 2 represents 3D scattered diagram of 35 genotypes of brinjal on the basis of first three principal components scores. The first principal component alone explains about $21.11 \%$ of the gross variability among the accessions which was mainly due to days to $50 \%$ of flowering (DF), leaf area per plant at $50 \%$ flowering (LA), photosynthetic rate at $50 \%$ flowering (PR), number of seeds per fruit (NS), fruit girth (FG), average fruit weight (FW) and total phenol content (TPC). Second principal component accounted for $13.07 \%$ of overall variability originating primarily from transpiration rate at $50 \%$ flowering (TR), stomatal conductance at $50 \%$ flowering (SC), number of fruits per plant (NF), fruit girth (FG), total phenol content (TPC) and total soluble sugar (TSS). The third principal component accounted for $11.32 \%$ of the total variation due to plant height $(\mathrm{PH})$, number of branches per plant (NB) and total phenol content (TPC).

The fourth principal component which explains about $9.83 \%$ of total variation mainly due to plant height $(\mathrm{PH})$, leaf area per plant at $50 \%$ flowering (LA), transpiration rate at 50 $\%$ flowering (TR), fruit length (FL) and total phenol content (TPC). On the other hand fifth principal component which accounted for $8.11 \%$ of the total variability was due to chlorophyll content at $50 \%$ flowering (CC), number of fruits per plant (NF) and total phenol content (TPC).

The sixth principal component which explains $7.29 \%$ of the total variability was largely due to total soluble sugar (TSS), fruit yield per plant (FY), chlorophyll content at $50 \%$ flowering (CC) and plant height (PH). Kumar et al., (2016) conducted principal component analysis of 33 genotypes of eggplant which indicated that the first 6 principal components with an Eigen value $>2$ contributed about $80.61 \%$ of total variability. Flowering time, fruit circumference, fruit width, total phenol content, inter-nodal length, leaf area index, fruit yield per plant and average fruit weight were traits contributing most to the total variability. Sunseri et al., (2010) studied seventy entries of eggplant for estimation of genetic diversity using PCA and revealed first three components that accounted for $74 \%$ of the total variance.

Quamruzzaman et al., (2009) reported that role of fruit yield in eggplant was more important towards genetic divergence. Solaiman et al., (2014) reported that fruit width, fruit weight and fruit yield per plant were important traits contributing towards divergence of the genotypes. The number of fruits per plant, fruit yield per plant and fruit width in both vectors was positive across two axis indicating they are important components of genetic divergence among these characters (Rahman et al., 2014).

From these results it can be concluded that characters like plant height $(\mathrm{PH})$, leaf area per plant at $50 \%$ flowering (LA), transpiration rate at $50 \%$ flowering (TR), chlorophyll content at $50 \%$ flowering (CC), number of fruits per plant (NF), fruit girth (FG), total 
phenol content (TPC) and total soluble sugar (TSS) could be used as characters to distinguish the germplasm of brinjal in the heavy rainfall zone of South Gujarat.

\section{Acknowledgement}

We thank J. R. Mavani for giving valuable inputs and Dr. K. G. Modha, Dept. of Genetics and Plant Breeding, NAU for comments that greatly improved the manuscript.

\section{References}

Anonymous 2015. Pocketbook of Agricultural Statistics 2015. Directorate of Economics and Statistics, GOI.

Harman, H. H. 1976. Modern Factor Analysis $3^{\text {rd }}$ ed. University of Chicago Press, Chicago. pp. 376.

Kaiser, H. F.1960. The applications of electronic computers to factor analysis, $E d s$. Psychol. Meas., 20: 141-151.

Kashyap, V., Kumar, S., Collonier, C., Fusari, F., Haicour, R., Rotino, G. L., Sihachak, R. D. and Rajam, M. V. 2003. Biotechnology of eggplant. Scientia Hort., 97(1): 1-25.

Sharma, J. R.1998.Stastical and Biometrical Techniques in Plant Breeding. New Age International (P) Limited Publishers, New Delhi. Pp. 432.

Sihachakr, D., Daunay, M.C., Serraf, I., Chaput, M.H., Mussio, I., Haricourt, R., Rotino, L. and Ducreux, G. 1994. Somatic hybridization of eggplant (Solanum melongena L.) with its close and wild relatives. Biotechnology in Agriculture and Forestry: Somatic Hybridization in Crop
Improvement. Pp. 255- 278.

Lester, R. N. and Hasan, S. M. Z. 1991. Origin and domestication of the eggplant, Solanum melongena L., from Solanum incanum. Solanaceae III: Taxonomy, Chemistry, Evolution. Pp. 369-387.

Kumar, S. R., Arumugam, T. and Ulaganathan V. 2016. Genetic diversity study in eggplant germplasm by principal component analysis. SABRAO Journal of Breeding and Genetics, 48(2): 162-171.

Salunkhe, D. K. and Kadam, S. S. 1998. Handbook of Vegetable Science and Technology: Production, Composition, Storage and Processing. Pp. 225.

Solaimana, A. H. M., Nishizawab, T., Khatuna, M.S., Ahmade 2014. Morphological characterization and genetic diversity studies of promising brinjal genotypes for hybridization program in Bangladesh. $J$ Adv. Agric. 3: 225-234.

Sunseri, F.G.B., Polignano, Alba, V., Lotti, C., Bisignano, V., Mennella, G., Alessandro, A. D., Bacchi, M., Riccardi, P., Fiore, M. C. and Ricciardi, L. 2010. Genetic diversity and characterization in African eggplant germplasm collection. African Journal of Plant Science, 4(7): 231-241.

Quamruzzaman, A.K.M., Rashid, M.A., Ahmad, S., Moniruzzaman, M. 2009. Genetic divergence analysis in eggplant (Solanum melongena L.). Bangladesh $J$. Agric. Res. 34: 705-712.

Rahman, M. O., Rabbani, M. G., Yesmin, R., Garvey, E. J. 2014. Genetic diversity of brinjal (Solanum melongena L.) through multivariate analysis. Int. J. Nat. Soc. Sci., 1: 85-93.

\section{How to cite this article:}

Savankumar N. Patel, Raj C. Popat, Priya A. Patel and Vekariya, R.D. 2018. Genetic Diversity Analysis in Brinjal (Solanum melongena L.) Genotypes: A Principal Component Analysis Approach. Int.J.Curr.Microbiol.App.Sci. 7(01): 3296-3301. doi: https://doi.org/10.20546/ijcmas.2018.701.392 